\title{
Research on the relationship between Work pressure and Safety performance of Aircraft maintenance
}

\author{
Siyu Zhang \\ Wuhan University of Technology, Wuhan 430000, China \\ 793232462@qq.com
}

Keywords: Civil aviation; Aircraft maintenance personnel; Work pressure; Safety performance.

\begin{abstract}
The particularity of the civil aviation industry determines that no matter what kind of accident happens, it will not only endanger the lives of the people, cause heavy losses to the national economy, but also have a negative impact on social stability. Therefore, the importance of ensuring the safety of civil aviation is self-evident. How to adjust the work pressure of the Aircraft maintenance personnel properly, and control the safety performance within a reasonable range has become the key to guarantee the safety of civil aviation. This paper constructs the Work pressure - Safety performance method, and analyzes the data of empirical study by using spss22.0. The results show that there is a significant correlation between work pressure and safety performance. The stress of role conflict and the number of role overload is negatively related to the personal safety performance. The stress of the quality of role overload and career development is negatively related to safety performance. The stress of responsibility to others and safety performance is positively related. According to the results, this paper proposes a few countermeasures for improving Aircraft maintenance personnel's Safety performance.
\end{abstract}

\section{Introduction}

Under the influence of national economy and the improvement of people's living standard, the civil aviation transportation industry in China has developed rapidly. With its growth, the pressure of aviation safety is growing. How to ensure the safety of civil aviation is becoming an urgent problem. According to the research in aviation, the maintenance error of Aircraft maintenance personnel has become one of the main causes of aviation accidents. Higher work pressure not only cause the physical and psychological to produce all kinds of adverse reactions, but also become an important inducement that directly cause the Aircraft maintenance personnel to make mistakes and safety accident. Therefore, make sure all of us fully understand the relationship between the pressure source and the safety performance of Aircraft maintenance personnel has important practical significance for improvement of aviation safety level.

This paper through rebuilding the relational model between work pressure and safety performance, designing the questionnaire and analyzing, in order to explore the specific influence between work pressure and safety performance. Then propose the corresponding solutions to help airlines to improve the safety performance of Aircraft maintenance personnel, enhance the safety and efficiency of civil aviation industry.

\section{The summary of the research}

At present, it is not mature for the relationship between work pressure and safety performance, but it is well developed in their respective fields. Tan Xin (2006) believes that the work pressure sources for Aircraft maintenance personnel include the following four aspects: the pressure from the task itself, the pressure from the management system, the pressure from the interpersonal relationships and the career development pressure. Both Walt Schafer (2009) and Xu Xiao Dong (2004) argue that we could not say stress is good or bad, different states can cause employees to react differently, and thus drive things to a negative or positive direction. In terms of safety performance, Zhang Peng-Peng (2008) 
classified the safety performance evaluation system into two types of outcome indicators and process indicators based on the Riesen model, and assessed the safety of the airline companies overall and locally by using hierarchical fuzzy comprehensive evaluation. Wang Yong Gang and Wang Can Min (2013) put forward the factors that affect the safety performance of airlines including the legal supervision and management of airline companies and the human factors of airline workers.

\section{Research design}

\subsection{Research Hypotheses}

$\mathrm{H} 1$ : role ambiguity is negatively correlated with personal safety performance.

$\mathrm{H} 2$ : role ambiguity is negatively correlated with the organization safety performance.

H3: role conflict is negatively correlated with personal safety performance.

$\mathrm{H} 4$ : role conflict is negatively correlated with the organization safety performance.

H5: the numbers of role overload is negatively correlated with personal safety performance.

H6: the numbers of role overload is negatively correlated with the organization safety performance.

H7: the quality of role overload is negatively correlated with personal safety performance.

H8: the quality of role overload is negatively correlated with the organization safety performance.

H9: career development is negatively correlated with personal safety performance.

H10: career development is negatively correlated with the organization safety performance.

H11: responsibility to others is negatively correlated with personal safety performance.

H12: responsibility to others is positively correlated with the organization safety performance.

\subsection{Variables and Theoretical Model}

This paper takes Internet R\&D personnel as the research object, takes role ambiguity, role conflict, the numbers of role overload, the quality of role overload, career development and responsibility to others as independent variables, takes personal safety performance and the organization safety performance as a dependent variable. Through the construction of the model, this paper explains the predictive effect of work pressure on safety performance. The specific model shown below:

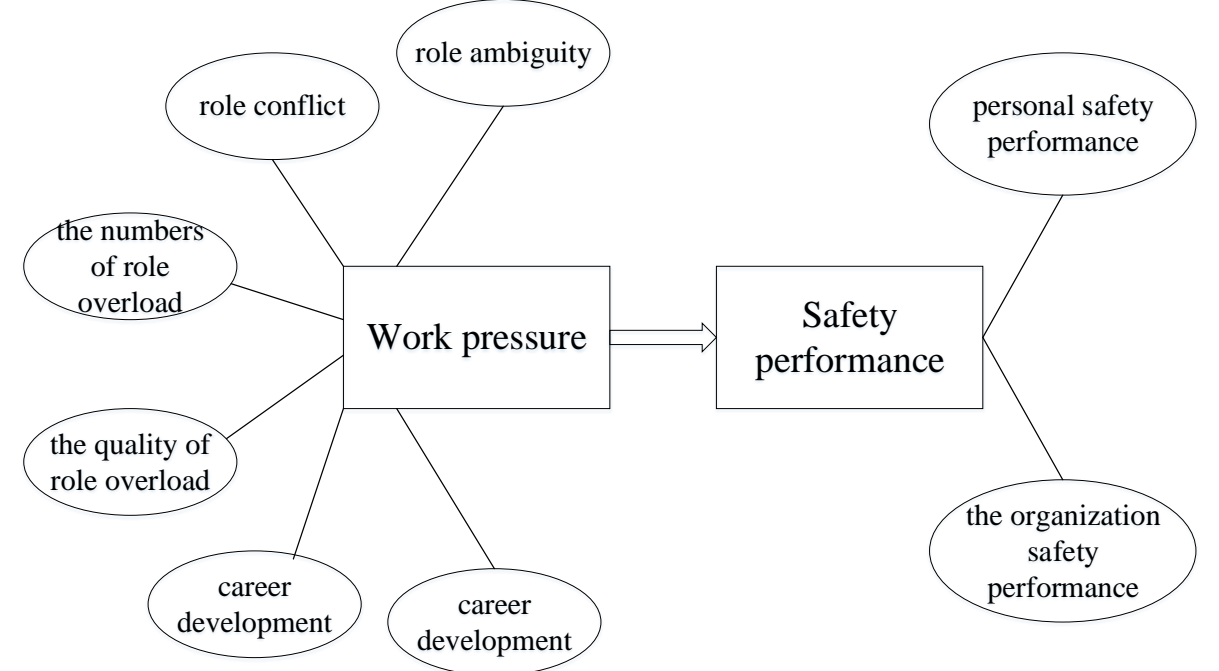

\subsection{Questionnaire Design}

Figure 1 Theoretical model

The entire questionnaire is divided into three parts:

The first part: personal basic information. Mainly include gender, age, academic qualifications and length of service.

The second part: work pressure scale. This scale was based on the stress diagnostic scale prepared by Ivancevich (1980).It divides work pressure into six dimensions and is evaluated according to the Likert seven-point scale. However, it is due to the fact that the Aircraft maintenance personnel of this survey are engineering technicians, it might be difficult for them to be highly sensitive to understand 
these language. So in order to make it easier for them to clearly choose the description which conforms to the actual situation, this scale will change it to Likert five-point scale.

The third part: work pressure scale. This scale mainly refers to the safety performance scale of Zhang Wei (2008), who modified it by Motowidlo (1994), Neal and Griffin (1997). It divides safety performance into personal safety performance and the organizational safety performance, and uses the Likert five-point scale.

\section{Empirical analysis}

\subsection{Data Source}

This research mainly aims at the Aircraft maintenance personnel of China Eastern Airlines in Wuhan. A total of 136 formal questionnaires were issued and 130 were returned. The effective rate of the questionnaire recovery was $95.59 \%$.

\subsection{Reliability and Validity Analysis of Questionnaire}

This paper analyzed the data of empirical study with the help of spss22.0. The Cronbach's Alpha of the work pressure scale is 0.873 , Safety performance scale's is 0.784 . Both two scales are above 0.796 , which means the reliability of the scale is grateful. As for validity analysis, the KMO of work pressure scale is 0.757 , and the KMO of work pressure scale is 0.842 . Therefore, it can be considered that the scale of this study is in line with the needs of the research and can carry out the next research.

\subsection{Regression Analysis}

In model 1, the unstandardized coefficients of the "the quality of role overload" is -0.367 , the $t$ value is -4.994 , and the significant $P$ value is 0.000 . In model 2, the unstandardized coefficients of the two independent variables are -0.358 and 0.130 . Respectively, and the regression coefficient t-test was significant. However, the unstandardized coefficients of the three independent variables of model 3 were $-0.282,0.125$ and -0.161 . So regression analysis equations can be established like this:

Personal safety performance $=3.039-0.282^{*}$ the quality of role overload $+0.125^{*}$ responsibility to others $-0.161 *$ the numbers of role overload

Table1 Regression analysis results

\begin{tabular}{|c|c|c|c|c|c|c|}
\hline \multirow{2}{*}{} & \multirow{2}{*}{ Model } & \multicolumn{2}{|c|}{$\begin{array}{c}\text { Non-standardized } \\
\text { Coefficient }\end{array}$} & $\begin{array}{c}\text { Standard } \\
\text { Coefficient }\end{array}$ & \multirow{2}{*}{$\mathrm{T}$} & \multirow{2}{*}{ Sig. } \\
\cline { 3 - 7 } \multicolumn{2}{|c|}{} & B & Standard error & Beta & & \\
\hline \multirow{3}{*}{1} & (constant) & 3.173 & 0.294 & & 10.794 & 0 \\
\hline \multirow{3}{*}{2} & the quality of role overload & -0.367 & 0.073 & -0.404 & -4.994 & 0 \\
\cline { 2 - 7 } & (constant) & 2.74 & 0.349 & & 7.842 & 0 \\
\cline { 2 - 7 } & the quality of role overload & -0.358 & 0.072 & -0.394 & -4.94 & 0 \\
\cline { 2 - 7 } & responsibility to others & 0.13 & 0.058 & 0.177 & 2.217 & 0.028 \\
\hline \multirow{4}{*}{3} & (constant) & 3.039 & 0.374 & & 8.122 & 0 \\
\cline { 2 - 7 } & the quality of role overload & -0.282 & 0.08 & -0.311 & -3.517 & 0.001 \\
\cline { 2 - 7 } & responsibility to others & 0.125 & 0.058 & 0.171 & 2.17 & 0.032 \\
\cline { 2 - 7 } & the numbers of role overload & -0.161 & 0.078 & -0.183 & -2.066 & 0.041 \\
\hline
\end{tabular}

PS: a. dependent variable: Personal safety performance

In model 1 , the unstandardized coefficients of the "the quality of role overload" is -0.229 , the $t$ value is -2.935 , and the significant $P$ value is 0.004 . In model 2 , the unstandardized coefficients of the two independent variables are -0.226 and 0.214 . Respectively, and the regression coefficient t-test was significant. So regression analysis equations can be established like this:

The organization safety performance $=2.295-0.266^{*}$ career development $+0.214^{*}$ responsibility to others. 
Table 2 Regression analysis results

\begin{tabular}{|c|c|c|c|c|c|c|}
\hline \multicolumn{2}{|c|}{\multirow{2}{*}{ Model }} & \multicolumn{2}{|c|}{$\begin{array}{c}\text { Non-standardized } \\
\text { Coefficient }\end{array}$} & $\begin{array}{c}\text { Standard } \\
\text { Coefficient }\end{array}$ & \multirow{2}{*}{ T } & \multirow{2}{*}{ Sig. } \\
\cline { 3 - 7 } \multicolumn{2}{|c|}{} & B & Standard error & Beta & & \\
\hline \multirow{3}{*}{1} & (constant) & 3.071 & 0.376 & & 8.158 & 0 \\
\hline \multirow{3}{*}{2} & career development & -0.299 & 0.102 & -0.251 & -2.935 & 0.004 \\
\cline { 2 - 7 } & (constant) & 2.295 & 0.508 & & 4.518 & 0 \\
\cline { 2 - 7 } & career development & -0.266 & 0.101 & -0.223 & -2.622 & 0.01 \\
\cline { 2 - 7 } & responsibility to others & 0.214 & 0.096 & 0.19 & 2.234 & 0.027 \\
\hline
\end{tabular}

PS: a. dependent variable: the organization safety performance

In model 1, the unstandardized coefficients of the "the quality of role overload" is -0.361 , the $t$ value is -5.035 , and the significant $P$ value is 0.000 . In model 2 , the unstandardized coefficients of the two independent variables are -0.350 and 0.162 . Respectively, and the regression coefficient t-test was significant. So regression analysis equations can be established like this:

Safety performance $=2.690-0.35 *$ the quality of role overload $+0.162 *$ responsibility to others

Table 3 Regression analysis results

\begin{tabular}{|c|c|c|c|c|c|c|}
\hline & \multirow[t]{2}{*}{ Model } & \multicolumn{2}{|c|}{$\begin{array}{c}\text { Non-standardized } \\
\text { Coefficient }\end{array}$} & \multirow{2}{*}{$\begin{array}{c}\begin{array}{c}\text { Standard } \\
\text { Coefficient }\end{array} \\
\text { Beta }\end{array}$} & \multirow[t]{2}{*}{$\mathrm{T}$} & \multirow[t]{2}{*}{ Sig. } \\
\hline & & $\mathrm{B}$ & Standard error & & & \\
\hline \multirow{2}{*}{1} & (constant) & 3.23 & 0.287 & & 11.259 & 0 \\
\hline & the quality of role overload & -0.361 & 0.072 & -0.407 & -5.035 & 0 \\
\hline \multirow{3}{*}{2} & (constant) & 2.69 & 0.337 & & 7.988 & 0 \\
\hline & the quality of role overload & -0.35 & 0.07 & -0.394 & -5.009 & 0 \\
\hline & responsibility to others & 0.162 & 0.056 & 0.225 & 2.865 & 0.005 \\
\hline
\end{tabular}

PS:a. dependent variable: safety performance

\section{Conclusions and Countermeasures}

\subsection{Research Conclusion}

Through the previous statistical analysis, this study has completed the verification of the hypotheses. We summarized the empirical analysis results into the table:

Table 4 Summary of research results

\begin{tabular}{|c|c|c|c|}
\hline Research Hypotheses & Test Results & Research Hypotheses & Test Results \\
\hline H1 & not tenable & H7 & tenable \\
\hline H2 & not tenable & H8 & tenable \\
\hline H3 & tenable & H9 & tenable \\
\hline H4 & not tenable & H10 & tenable \\
\hline H5 & tenable & H11 & tenable \\
\hline H6 & not tenable & H12 & tenable \\
\hline
\end{tabular}

\subsection{Research on Countermeasures}

RATIONAL ALLOCATION OF WORK CONTENT

Re-analyzing and redesigning the work of Aircraft maintenance personnel can reduce the workload and eliminate the feeling of job burnout through the optimization of work content. At the same time, part of the work rights should be distributed and decentralized. So the employees' satisfaction with their work will enhance. And they will pay more attention to safety operations, improve work efficiency and quality.

\section{PROVIDE PROFESSIONAL SAFETY QUALITY TRAINING}

By organizing knowledge lectures to strengthen the ability of Aircraft maintenance personnel to carry out the stress response and enhance the safety quality. Learning from domestic and international accident cases, to enhance them awareness of job stress and coping skills, improve the sense of responsibility to others. 


\section{DESIGN CAREER DEVELOPMENT CHANNEL}

On the one hand, airlines must design a good path for career development and provide them with fair promotion opportunities. On the other hand, it is necessary for them to get the help by providing information, one-on-one interviews and other means, to help them better analyze and locate their career development.

\section{Acknowledgements}

The author acknowledge the financial support from the National Social Science Foundation of China (Grant No.15ZDC022; Grant No.17BGL209) and National Natural Science Foundation of China (Grant No.71373199).

\section{References}

[1] Watt Sheffer. 2009. Stress Management Psychology. China Renmin University Press.

[2] Xiaodong Xu, Xiaobin Meng. Work pressure: cop ing and managemen. Aviation Industry Press.

[3] Xin Tan.2012. "Preliminary preparation of working pressure source scale for Aircraft maintenance personnel ," Chinese Journal of Health Psychology, 20 (6): 858-860.

[4] Pengpeng Zhang.2008. "Study on Airline Safety Performance Evaluation," Civil Aviation University of China.

[5] Yonggang Wang, Can-min Wang.2013. "Analysis on the Influencing Factors of Airlines' Safety Performance Based on ISM and ANP,".Journal of Safety and Environment, 13 (4): 221-226. 